\title{
Behaviour of a Composite Concrete-Trapezoidal Steel Plate Slab in Fire
}

\author{
Tomaž Hozjan, Miran Saje, Igor Planinc, Stanislav Srpčič, Sebastjan Bratina \\ University of Ljubljana, Faculty of Civil and Geodetic Engineering, Ljubljana, Slovenia \\ E-mail: miran.saje@fgg.uni-lj.si \\ Received February 11, 2010; revised March 28, 2010; accepted April 4, 2010
}

\begin{abstract}
The present paper investigates fire resistance of a simply-supported composite concrete-trapezoidal steel sheet slab. The objective is to find out if a steel sheet, as a moisture diffusion barrier, may substantially effect the hydro-thermal situation in the concrete part of the cross-section. The numerical integration of the equations of a coupled hygro-thermal boundary-value problem (Tenchev, R.T., Li, L.Y. and Purkiss, J.A. (2001) Num. Heat Transfer Part A, 39(7), 685-710), with and without considering the barrier, shows that the barrier does not really effect the magnitude and the development of temperatures over the cross-section, while there is a significant effect on the pattern of moisture transport and the magnitude of vapour pressure. Particularly high magnitudes of vapour pressure (about 4.5 MPa) were shown in cases where the steel sheet was considered in analyses, which indicates a possible micro damage of concrete in the web of the section, although spalling probably cannot take place due to the steel sheet cover. As the typical composite slab investigated here is not sufficiently fire resistant without any additional reinforcement bars placed in the web, further investigations are directed to finding an optimal position and area of these bars. Following a simplified procedure given in EC2 (Eurocode 2, Design of Concrete Structures, Part 1.2 (2004) Structural fire design, European Committee for Standardization) and assuming that the present composite slab is subject to the uniform traction $q=1.52 \mathrm{kN} / \mathrm{m}$, yields that placing one bar with the area $1.153 \mathrm{~cm}^{2} 4 \mathrm{~cm}$ away from the edge suffices for the $60 \mathrm{~min}$ fire resistance of the slab.
\end{abstract}

Keywords: Fire Analysis, Composite Structures, Heat and Mass Transfer

\section{Introduction}

Composite concrete-trapezoidal steel plate slabs are widely used structural elements in buildings and bridges. During the placement of concrete the trapezoidal steel plate replaces panelling, while upon hardening of concrete the two materials work as a composite slab, the steel plate representing the reinforcement. For the better vertical load redistribution, concrete is additionally reinforced with a steel mesh at the upper part of the cross-section (here called the flange). The reinforcement in the web of the concrete part of the section needs rarely to be applied for non-accidental actions. By contrast, when the composite slab is exposed to fire, the steel plate is directly exposed to high temperatures resulting in a substantial decrease of its bearing capacity. The reinforcement in the web and its position within the concrete slab then become essential. In fact, both the position and the area of the additional reinforcement turn out to be essential issues of a safe fire design.

The knowledge of temperature and pore pressure distributions in the slab during fire is the key to fire resistance predictions. There are a number of mathematical models appropriate for the prediction of temperature field in the composite concrete-trapezoidal steel plate slab in fire. Luikov [1] was probably the first to introduce the theoretical basis for the coupled heat and moisture transfer through a permeable porous material such as concrete. His mathematical model is described by the system of two non-linear partial differential equations with permeability coefficients and thermodynamic characteristics of material being functions of the heat and moisture state. Luikov's model was later on improved by Bažant and Thonguthai [2]. Their model is enhanced by the capability of considering the dehydration process of chemically bound water in concrete, while free water evaporation and vapour condensation in concrete are neglected. The evaporation and condensation were later 
on accounted for by Davie, Pearce and Bičanić [3], Gawin, Pesavento and Schrefler [4] and Tenchev, Li and Purkiss [5]. Their models are now considered to be rather complete for the analysis of concrete structures in fire.

In the present paper, a somewhat modified model of Tenchev et al. [5] is employed to investigate the hygro -thermal behaviour of a composite concrete-trapezoidal steel plate slab in fire. This numerical model enables us to estimate the distribution of temperature, moisture and pore pressure over the concrete cross-section at any time during a fire. These are vital data for predicting the fire resistance time, and spalling of concrete [4]. A typical, simply supported composite floor of high-rise office buildings is being analysed, and the effect of the trapezoidal sheet as a moisture diffusion barrier on the distribution of temperature, pore pressure and free water content over the cross-section of the slab is being presented and discussed. Once the temperatures within the crosssection have been obtained, the fire resistance time at failure is estimated on the basis of the temperatures in the additional reinforcement bars of the concrete webs.

In what follows we make a short overview of the equations of heat and moisture transport in concrete and describe relevant variables; subsequently we discuss the hygro-thermal behaviour of the composite slab in fire.

\section{Heat and Moisture Transport in Concrete}

A coupled heat and moisture transfer in concrete, when exposed to fire, can be mathematically described by the system of mass conservation equations for each phase of concrete separately and with an energy conservation equation as follows [5]:

- Water conservation:

$$
\frac{\partial \bar{\rho}_{L}}{\partial t}=-\nabla \mathbf{J}_{L}-\dot{E}_{L}+\frac{\partial \bar{\rho}_{D}}{\partial t}
$$

- Water vapour conservation:

$$
\frac{\partial\left(\varepsilon_{G} \tilde{\rho}_{V}\right)}{\partial t}=-\nabla \mathbf{J}_{V}+\dot{E}_{L}
$$

- Air conservation:

$$
\frac{\partial\left(\varepsilon_{G} \tilde{\rho}_{A}\right)}{\partial t}=-\nabla \mathbf{J}_{A}
$$

- Energy conservation:

$$
(\underline{\rho C}) \frac{\partial T}{\partial t}=-\nabla \cdot(-k \nabla T)-(\underline{\rho C \mathbf{v}}) \cdot \nabla T-\lambda_{E} \dot{E}_{L}-\lambda_{D} \frac{\partial \bar{\rho}_{D}}{\partial t}
$$

In (1)-(3) $\rho_{i}$ denotes density of phase $i, \varepsilon_{G} \tilde{\rho}_{V}$ and $\varepsilon_{G} \tilde{\rho}_{A}$ represent mass concentration of air and water vapour per unit volume concrete, $\mathbf{J}_{i}$ is the mass flux of phase $i, \dot{E}_{L}$ is the rate of evaporation of free water (including desorption), $t$ is time. Index $i$ denotes the phase: $L$ is free water, $V$ is water vapour and $A$ is dry air. In (4) $\underline{\rho C}$ is heat capacity of concrete, $k$ is thermal conductiv- ity of concrete, $\underline{\rho C v}$ relates to the energy transferred by fluid flow, $\lambda_{E}$ is the specific heat of evaporation, $\lambda_{D}$ is the specific heat of dehydration, and $T$ is the absolute temperature in degrees Kelvin.

The mass fluxes of dry air, water vapour and free water can be expressed in terms of pressure and concentration gradients assuming that Darcy's and Fick's law are applicable and that the diffusion of adsorbed water on the surface of solid cement phase skeleton is negligible:

$$
\begin{gathered}
\mathbf{J}_{A}=\varepsilon_{G} \tilde{\rho}_{A} \mathbf{v}_{G}-\varepsilon_{G} \tilde{\rho}_{G} D_{A V} \nabla\left(\frac{\tilde{\rho}_{A}}{\tilde{\rho}_{G}}\right) \\
\mathbf{J}_{G}=\varepsilon_{G} \tilde{\rho}_{V} \mathbf{v}_{G}-\varepsilon_{G} \tilde{\rho}_{G} D_{V A} \nabla\left(\frac{\tilde{\rho}_{V}}{\tilde{\rho}_{G}}\right) \\
\mathbf{J}_{L}=\bar{\rho}_{L} \mathbf{v}_{L}
\end{gathered}
$$

The fluxes are defined per unit area of concrete. In Equations (5)-(7), $D_{A V}$ and $D_{V A}$ are the diffusion coefficients of dry air in water vapour and water vapour in dry air within the porous concrete, and $\mathbf{v}_{G}$ and $\mathbf{v}_{L}$ are the velocities of the gas and liquid water phases resulting from a pressure-driven flow as given by Darcy's law:

$$
\begin{aligned}
& \mathbf{v}_{G}=-\frac{K K_{G}}{\mu_{G}} \nabla P_{G} \\
& \mathbf{v}_{L}=-\frac{K K_{L}}{\mu_{L}} \nabla P_{L}
\end{aligned}
$$

Here $K$ is the intrinsic permeability of dry concrete, $K_{G}$ and $K_{L}$ are the relative permeabilities of the gas and liquid phases, $\mu_{G}$ and $\mu_{L}$ are their dynamic viscosities, and $P_{G}$ and $P_{L}$ are the corresponding pressures. Following the model of Tenchev et al. [5], we at this point assume that the liquid pressure is equal to the gas pressure, $P_{G}=P_{L}$. It is also assumed that air and water vapour behave as an ideal gas and that the content of free water $\rho_{L}$ is determined by the help of the simplified sorption curves introduced by Bažant and Kaplan [6]. To achieve a better numerical stability and to avoid loss of convergence in the global iteration, we model sorption curves with polynomials of the third order, while its coefficients are temperature dependent [7].

After combining (1)-(2), we end up with three coupled partial differential equations describing the transfer of dry air and moisture, and energy conservation. The solution is obtained numerically by the finite element method using our original computer programme, where we consider temperature $T$, pore pressure $P_{G}$ and water vapour content $\tilde{\rho}_{V}$ as the primary unknowns of the problem. Further technical details are given in, e.g. [5].

\section{The Transfer of Heat and Moisture over the Cross-Section of the Composite Slab}

The composite slab is exposed to standard fire accord- 
ing to ISO 834 [8]. Figure 1 presents the geometric and loading data along with the $2 \mathrm{D}$ finite-element mesh of the heat and moisture transfer analysis over the crosssection of the composite slab. Due to its symmetry only one half of one wave of the cross-section is accounted for. We consider two different boundary conditions. In the first set of boundary conditions (case A1), we consider the trapezoidal steel sheet on the lower surface (denoted as edge 1 in Figure 1) to be the diffusion barrier. This way no transfer of moisture through the lower surface is possible. In the second set of boundary conditions (case A2), we neglect any effect of the steel sheet on the moisture flux. The moisture flux through the top surface (denoted as edge 2) is regarded as possible.

The fire is assumed to emerge from below (edge 1), while the temperature of edge 2 remains constant $\left(20^{\circ} \mathrm{C}\right)$.

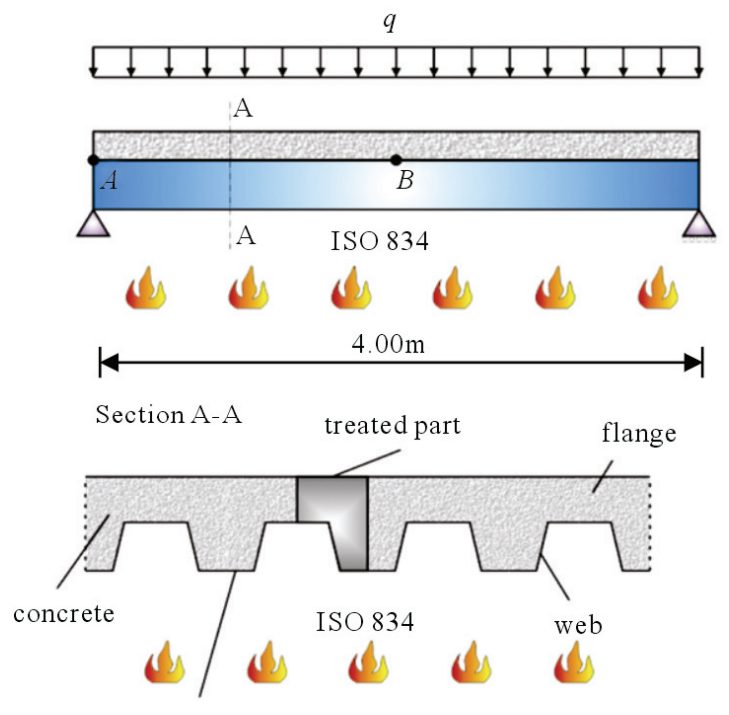

trapezoidal steel sheet
The boundary conditions are displayed in Table 1. The remaining data needed in the analysis are: density of concrete $\rho_{\mathrm{c}}=2400 \mathrm{~kg} / \mathrm{m}^{3}$, density of cement $\rho_{\text {cem }}=300$ $\mathrm{kg} / \mathrm{m}^{3}$, temperature $T_{0}=20^{\circ} \mathrm{C}$, initial pore pressure $P_{G, 0}=0.1 \mathrm{MPa}$, initial water vapour content $\tilde{\rho}_{V, 0}=0.0111 \mathrm{~kg} / \mathrm{m}^{3}$, water vapour content on boundary $\tilde{\rho}_{V, \infty}=0.0089 \mathrm{~kg} / \mathrm{m}^{3}$, initial porosity of concrete $p_{\text {or }}^{0}=0.15$, initial permeability of concrete $K=1 \cdot 10^{-16}$ and initial free water amount $\bar{\rho}_{L, 0}=10 \mathrm{~kg} / \mathrm{m}^{3}$. The heat transfer coefficient and emissivity on edge 1 are assumed to be equal to $h_{q}=25 \mathrm{~W} / \mathrm{m}^{2} \mathrm{~K}$, while the heat transfer coefficient on edge 2 is $h_{q}=9 \mathrm{~W} / \mathrm{m}^{2} \mathrm{~K}$. According to EC2 [9] emissivity on edge 2 is neglected. The time step employed in the numerical time integration equals $0.5 \mathrm{~s}$.

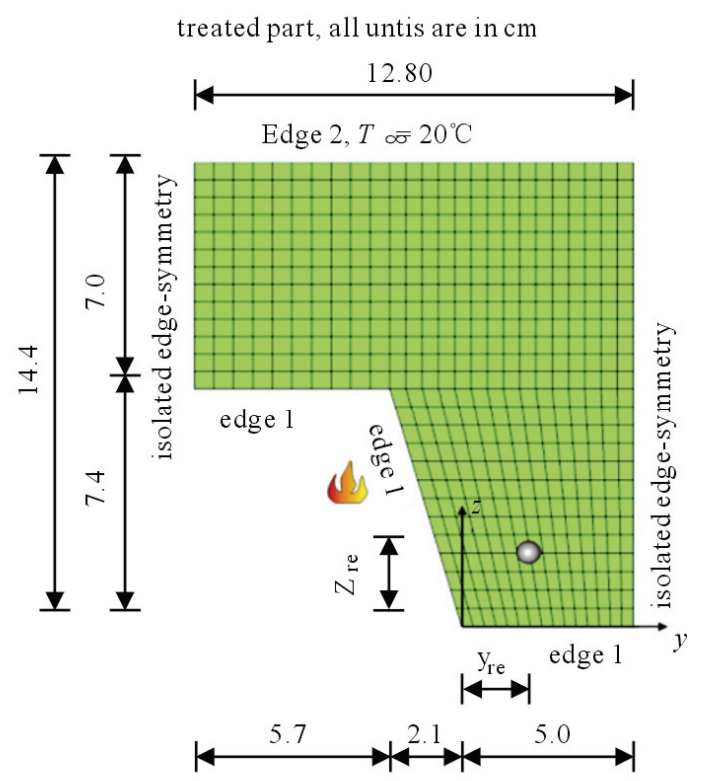

Figure 1. The composite plate and 2D finite element mesh over the concrete cross-section.

Table 1. Boundary conditions of composite slab.

\begin{tabular}{|c|c|c|c|c|}
\hline case & & edge 1 & edge 2 & symmetry \\
\hline \multirow{3}{*}{ A1 } & $T$ & $q_{T}=q_{T}\left(T_{150834}\right)$ & $q_{T}=q_{T}\left(T_{\infty}=20^{\circ} \mathrm{C}\right)$ & $\frac{\partial T}{\partial n}=0$ \\
\hline & $P_{G}$ & $\frac{\partial P_{G}}{\partial n}=0$ & $P_{G}=0.1 \mathrm{MPa}$ & $\frac{\partial P_{G}}{\partial n}=0$ \\
\hline & $\tilde{\rho}_{V}$ & $\frac{\partial \tilde{\rho}_{V}}{\partial n}=0$ & $q_{V}=q_{V}\left(\tilde{\rho}_{V, \infty}\right)$ & $\frac{\partial \tilde{\rho}_{V}}{\partial n}=0$ \\
\hline \multirow{3}{*}{ A 2} & $T$ & $q_{T}=q_{T}\left(T_{150834}\right)$ & $q_{T}=q_{T}\left(T_{\infty}=20^{\circ} \mathrm{C}\right)$ & $\frac{\partial T}{\partial n}=0$ \\
\hline & $P_{G}$ & $P_{G}=0.1 \mathrm{MPa}$ & $P_{G}=0.1 \mathrm{MPa}$ & $\frac{\partial P_{G}}{\partial n}=0$ \\
\hline & $\tilde{\rho}_{V}$ & $q_{V}=q_{V}\left(\tilde{\rho}_{V, \infty}\right)$ & $q_{V}=q_{V}\left(\tilde{\rho}_{V, \infty}\right)$ & $\frac{\partial \tilde{\rho}_{V}}{\partial n}=0$ \\
\hline
\end{tabular}


The development of the temperature field over the cross-section of the slab at 15,30 and $60 \mathrm{~min}$ is presented in Figure 2. Although the slab is exposed to the standard fire according to ISO 834, in which case the initial heating rate is rather high, an overall heating of the composite section is quite slow. Figure 2 shows that at 60 minutes the isothermal for $500^{\circ} \mathrm{C}$ stays rather close to the lower edge, i.e., only about $2.5 \mathrm{~cm}$ away. According to the simplified method in EC2, Annex B [9], the contour line T = $500^{\circ} \mathrm{C}$ is important in determining the fire resistance of the composite slab exposed to fire, enabling one to neglect the part of concrete whose temperature is greater than $500^{\circ} \mathrm{C}$.

To assess the effect of steel sheet as the diffusion barrier, we present in Figure 3 the increase of temperatures with time in some characteristic points within the web of the cross-section, whose positions are convenient for placing additional reinforcement bars to achieve a sufficient fire resistance. The coordinates of the points are presented in Table 2. The comparison of the results for cases A1 and A2 shows that the temperatures differ only a little and that the increase of temperature is slower in case A1. Similar results have been obtained for the same class of composite cross-sections of various height dimensions by separate numerical investigations. Thus we can conclude that the steel sheet essentially does not affect the temperatures.

As observed from Figure 3, the temperature gradient at characteristic points $\mathrm{A}, \mathrm{B}, \mathrm{C}$ and $\mathrm{D}$ at $60 \mathrm{~min}$ is about $65^{\circ} \mathrm{C}$ per $1 \mathrm{~cm}$, which results in the temperature decrease between points $A$ and $D$ to be roughly $200^{\circ} \mathrm{C}$ per $2.5 \mathrm{~cm}$. It is now clear that we can increase the fire resistance of the composite slab substantially, if we change the position of the bars for only a few centimeters away from the lower surface of the composite slab. Note that such a change of the position results in a somewhat smaller static height. This should not be critical during fire when the imposed actions and the safety factor are assumed smaller than regularly.

(a) temperature $T\left[{ }^{\circ} \mathrm{C}\right]$, case $\mathrm{A} 1$

$$
t=15 \mathrm{~min}
$$

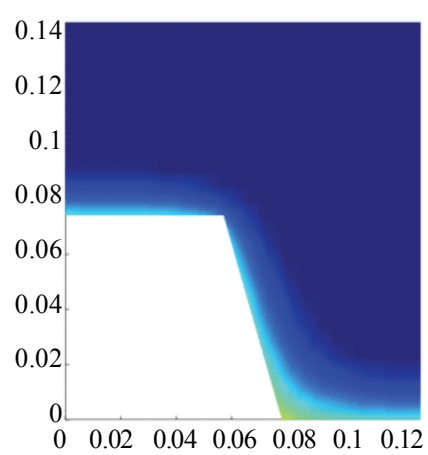

$$
t=30 \mathrm{~min}
$$

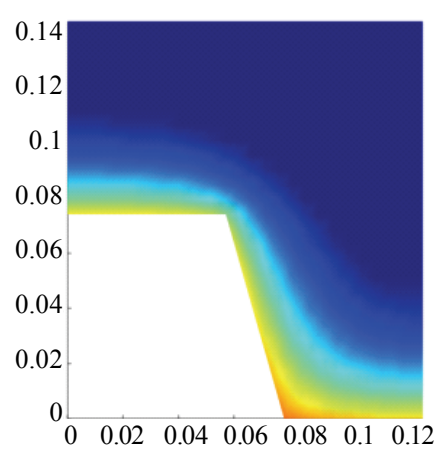

$t=60 \mathrm{~min}$

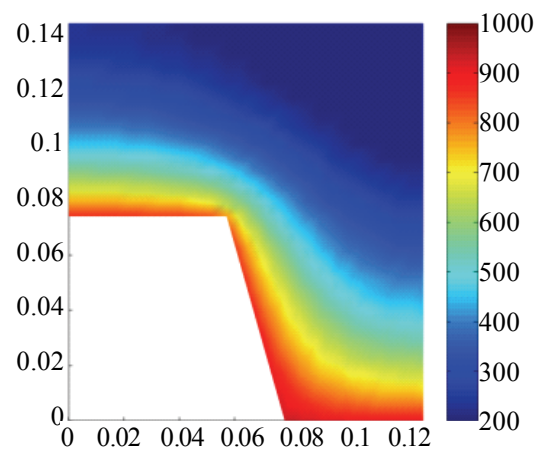

Figure 2. Distribution of temperature over the cross-section.

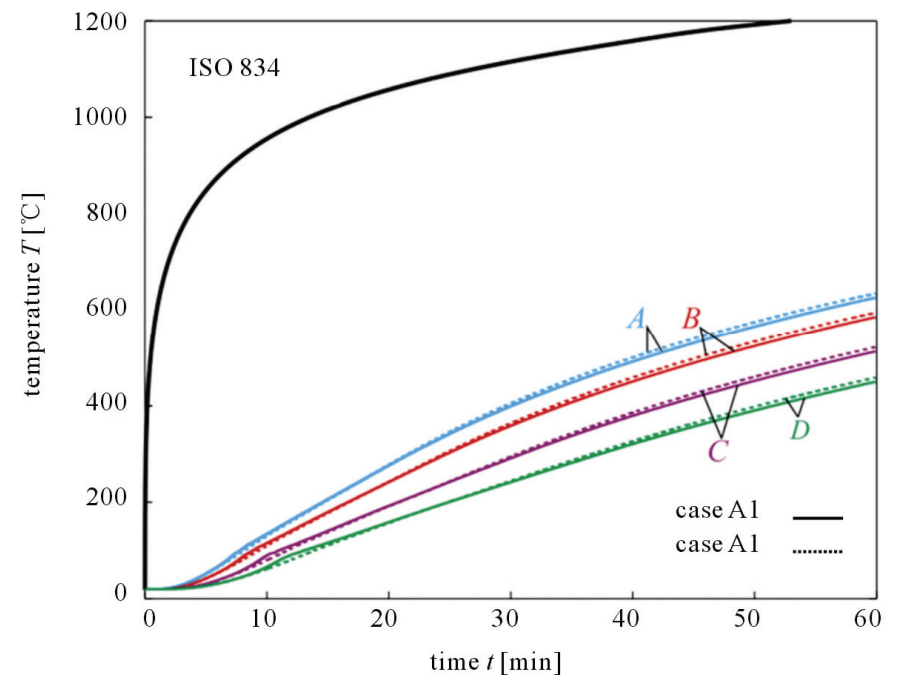

Figure 3. Variation of temperature with time in points $A, B, C$ and $D$. 
Table 2. Coordinates of characteristic points $A, B, C, D$.

\begin{tabular}{ccc}
\hline point & $y_{\text {re }}[\mathrm{cm}]$ & $z_{\text {re }}[\mathrm{cm}]$ \\
\hline$A$ & 2.5 & 2.5 \\
$B$ & 2.5 & 3 \\
$C$ & 2.5 & 4 \\
$D$ & 2.5 & 5 \\
\hline
\end{tabular}

While the steel sheet as a diffusion barrier has only a small effect on the temperature distributions, its effect on pore pressures is substantial. This is clearly seen in Figure 4. In case A1, where the transfer of water and water vapour through edge 1 is blocked, the whole amount of free water and water vapour is pushed by the temperature and pore pressure gradients towards edge 2 . This is depicted in Figure 5, showing the distribution of free water content over the cross-section at various instants. Beyond $200^{\circ} \mathrm{C}$ the chemically bounded water starts releasing and further increases the volume of free water (Figure 5(a)). At some point a full saturation of pores takes place which causes the substantial rise of the pore pressure. This is more pronounced in case A1, where the magnitude of pore pressure at $30 \mathrm{~min}$ is about $4.5 \mathrm{MPa}$ and is almost homogeneous over the web of the concrete slab (Figure 4(a)). By contrast, in case A2 (Figure 4(b)), vapour can also escape through the lower edge; in fact, the inspection of the results shows that moisture is largely released through the lower edge.

As a result, the magnitude of the pore pressure in concrete is in this case significantly lower (less than $3 \mathrm{MPa}$ ) both in the flange and in the web of the cross-section. Comparing the distributions of free water content over the cross-section (Figure 5) shows that the patterns are similar, yet the magnitudes of the water content are different. It is obvious that the effect of the steel sheet on the water content is high due to impervious edge 1 .

The results prove that the steel sheet plays a significant role in the distribution of pore pressures as well as their magnitudes. While this may result in damage of concrete and the contact between concrete and steel sheet, it is still not clear if solely high pressures could be responsible for explosive spalling of concrete. The absence of explosive spalling may, however, be due to the damaged contact between the steel sheet and concrete. Some water vapour could therefore escape either through the lower edge or in the axial direction, causing drop in the pore pressure. Numerous studies also show that pore pressures need not be the main reason for explosive spalling of concrete to occur $[4,10]$.

(a) pore pressure $P_{G}[\mathrm{MPa}]$,case $\mathrm{A} 1$

$t=15 \mathrm{~min}$

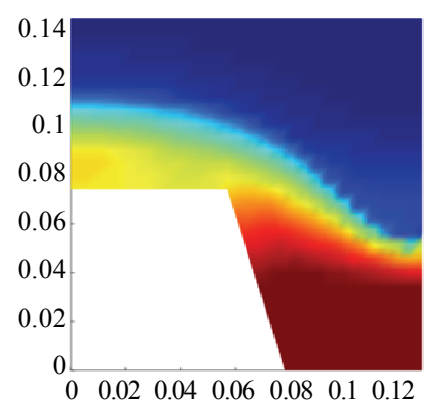

(b) pore pressure $P_{G}[\mathrm{MPa}]$, case $\mathrm{A} 2$

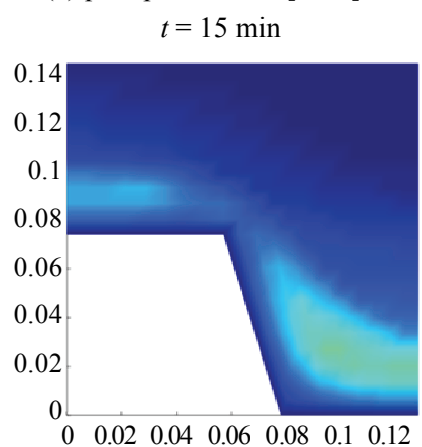

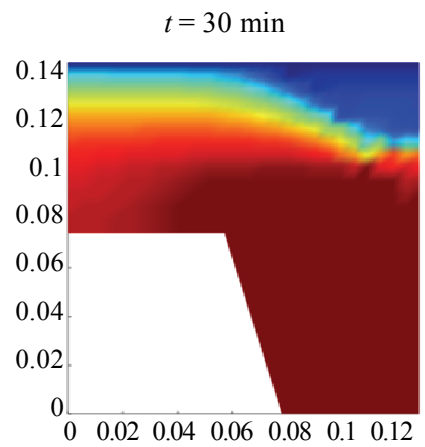

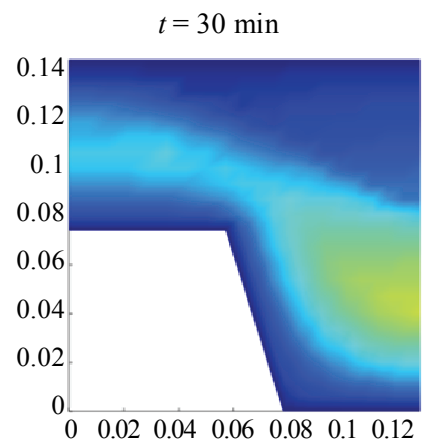

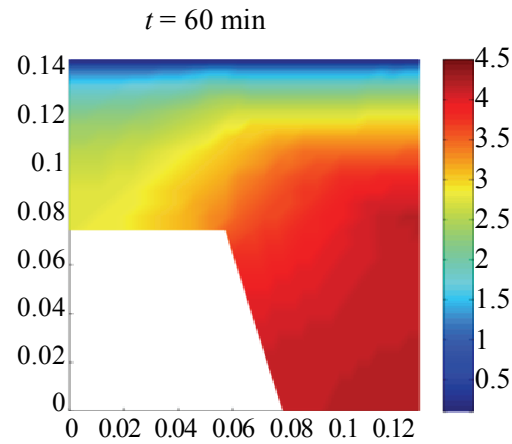

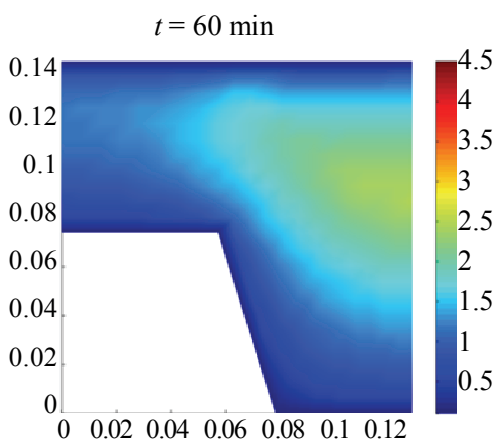

Figure 4. Distribution of pore pressures over the cross-section at $t=15,30$, and $60 \mathrm{~min}$. (a) case A1; (b) case A2. 
(a) free water content $\bar{\rho}_{F W}\left[\mathrm{~kg} / \mathrm{m}^{3}\right]$, case A1

$$
t=15 \mathrm{~min}
$$

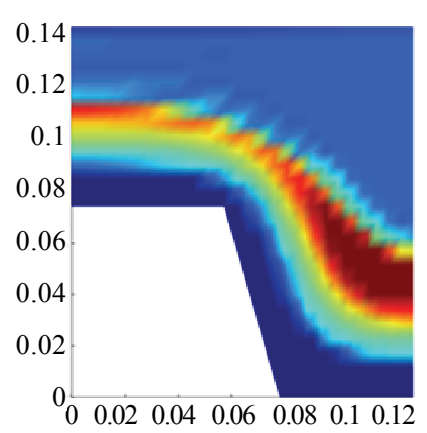

$t=30 \mathrm{~min}$

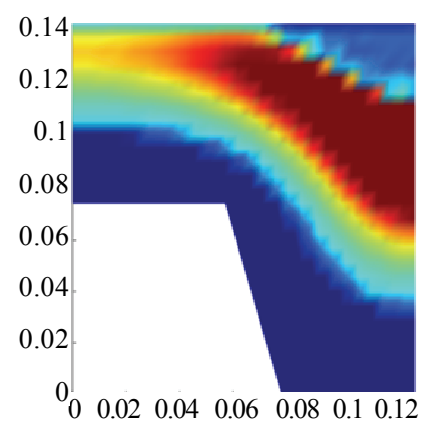

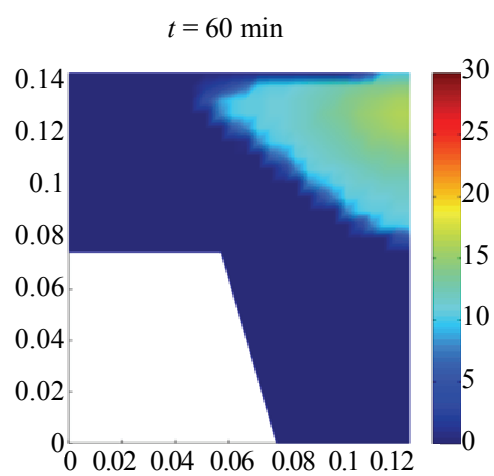

(b) free water content $\bar{\rho}_{F W}\left[\mathrm{~kg} / \mathrm{m}^{3}\right]$,case A2
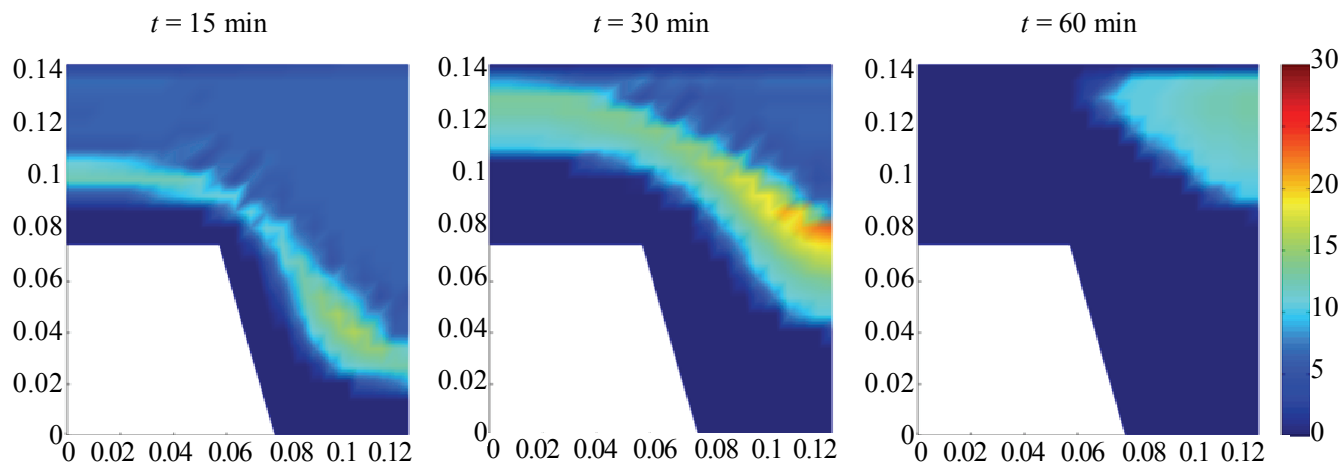

Figure 5. Distribution of free water content over the cross-section at $t=15,30$, and 60 min. (a) case A1; (b) case A2.

(a)ISO 834

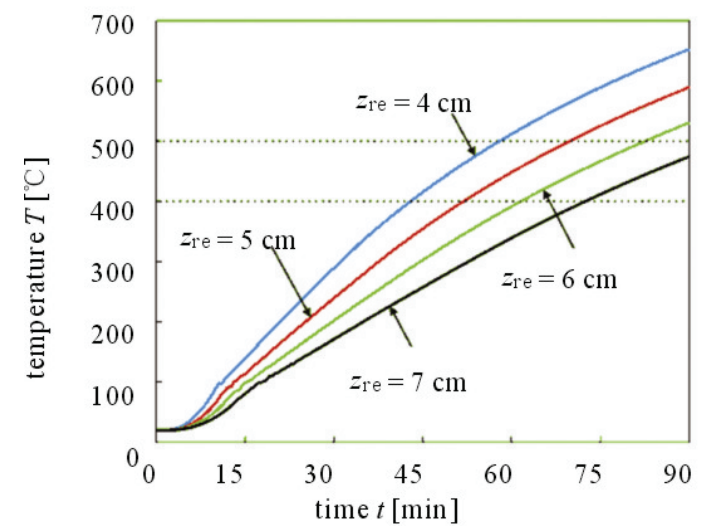

(b)ISO 834

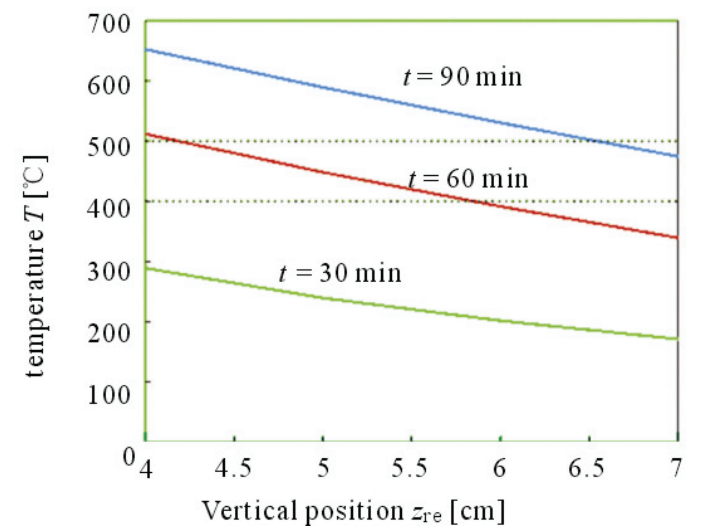

Figure 6. (a) Variation of temperature with time for different vertical positions of reinforcement bars; (b) Variation of temperature with vertical position $z_{\mathrm{re}}$ at $t=30,60$, and $90 \mathrm{~min}$.

As the steel sheet is directly exposed to high temperatures, it loses its bearing capacity shortly after fire begins. The presence of additional reinforcement bars, if any, is essential in such cases. That is why fire resistance of composite slab in terms of the resistance time can be rather well estimated on the basis of actual temperatures in the additional reinforcement bars placed in the web. It is well known that creep strains of mild steel start increasing at about $400^{\circ} \mathrm{C}$ [11]. At roughly $500^{\circ} \mathrm{C}$, the creep strain rates become pronounced and dictate the failure of the slab. Therefore it is plausible to estimate the resistance time of the composite slab on the basis of the critical temperature in the additional reinforcement. Thus we may assume that loss of resistance is strongly related to the instant when the temperature of the additional reinforcement bar reaches $500^{\circ} \mathrm{C}$. Figure 6(a) shows the time development of temperatures at various vertical locations, $z_{\mathrm{re}}$, appropriate for placing additional 
reinforcement bars in the cross-section. The horizontal position of the bars is kept at $y_{\mathrm{re}}=2.5 \mathrm{~cm}$ in all cases. As expected, the rise of temperature in the reinforcement bar is smaller for bars placed higher. The critical temperature, $T_{\text {cr }}=500^{\circ} \mathrm{C}$, for $z_{\mathrm{re}}=4 \mathrm{~cm}$ is reached in $58 \mathrm{~min}$ and for $z_{\mathrm{re}}=6 \mathrm{~cm}$ in $83 \mathrm{~min}$. A big difference in time compared to a relatively small change in the vertical position is noticeable. This becomes even more clear in Figure 6(b), where the dependency of temperature on the vertical position $z_{\mathrm{re}}$ is presented for $t=30,60$, and $90 \mathrm{~min}$.

The idea of a critical temperature can serve as a means to develop a method for a simplified design. Once the fire resistance class (in minutes) and the position of the additional reinforcement bar have been decided on, the temperature of the bar is obtained from the temperaturetime distributions over the cross-section found by the numerical analysis. Finally, using the simplified EC2 [9] Annex procedure gives the minimum area of the steel bar.

The above procedure has been validated by the nonlinear mechanical analysis [7] of the simply supported beam discussed here (Figure 1), subjected to the uniform non-accidental external load $q=1.52 \mathrm{kN} / \mathrm{m}$ [7]. Assuming $z_{\mathrm{re}}=4 \mathrm{~cm}$ and class R60 (i.e., the $60 \mathrm{~min}$ fire resistance time), the above proposed simplified EC2 [9] procedure yields the area of the bar $1.153 \mathrm{~cm}^{2}$. Using the above reinforcement data and the calculated temperature distributions in the non-linear mechanical analysis [7] gives the fire resistance time to be $69 \mathrm{~min}$. This rather accurate and conservative prediction of the fire resistance time proves that the graphs given in Figure 6 enable us to fairly accurately choose the position and the area of the additional reinforcement bars for a given fire resistance class. The details of the mechanical analysis [7] are out of the scope of the present paper and are here omitted.

\section{Discussion}

The simply-supported composite concrete-trapezoidal steel sheet slab is a widely used structural element in engineering. Often its fire resistance applied from below is of prime importance. The steel sheet acts as a moisture diffusion barrier. In order to find out if such a barrier may substantially affect the hydro-thermal situation in the concrete part of the cross-section, we compared the numerical results of the coupled hygro-thermal boundary-value problem obtained with and without considering the barrier. The results showed that the barrier does not really affect the magnitude and the development of temperatures over the cross-section, while the effect on the pattern of moisture transport and the magnitude of vapour pressure is significant. Particularly high magnitudes of vapour pressure (about 4.5 MPa) were experienced in analyses when considering the steel sheet, which indicates a possible micro damage of concrete in the web of the section, although explosive spalling probably cannot take place due to the steel sheet cover.

Our recent mechanical analyses have shown [7] that the composite slab investigated here is not sufficiently fire resistant without placing an additional reinforcement in the web. The objective of the present study was hence to find the area and optimal position of the steel reinforcement bar in the web such that its fire resistance is within a chosen time resistance class. Due to a slow temperature diffusion in concrete, a big difference in the resistance time follows after a small change in the vertical position of the bar. For the composite slab investigated herein, the area of $1.153 \mathrm{~cm}^{2}$ and the distance of only $4 \mathrm{~cm}$ away from the lower surface suffice for the 60 min fire resistance. The resistance time obtained this way is well in keeping with the resistance time obtained by the sophisticated mechanical analysis [7].

\section{References}

[1] A. V. Luikov, "Systems of Differential Equations of Heat and Mass Transfer on Capillary-Porous Bodies," International Journal of Heat and Mass Transfer, Vol. 18, No. 1, 1975, pp. 1-14.

[2] Z. P. Bažant and W. Thonguthai, "Pore Pressure and Drying of Concrete at High-Temperature," Journal of Engineering Mechanics Division-ASCE, Vol. 104, No. 5, 1978, pp. 1059-1079.

[3] C. T. Davie, C. J. Pearce and N. Bičanić, "Coupled Heat and Moisture Transport in Concrete at Elevated Temperatures - Effects of Capillary Pressure and Absorbed Water," Numerical Heat Transfer Part A, Vol. 49, No. 8, 2006, pp. 733-763.

[4] D. Gawin, F. Pesavento and B. A. Schrefler, "Towards Prediction of the Thermal Spalling Risk through a MultiPhase Porous Media Model of Concrete," Computer Methods in Applied Mechanics and Engineering, Vol. 195, No. 41-43, 2003, pp. 5707-5729.

[5] R. T. Tenchev, L. Y. Li and J. A. Purkiss, "Finite Element Analysis of Coupled Heat and Moisture Transfer in Concrete Subjected to Fire," Numerical Heat Transfer Part A, Vol. 39, No. 7, 2001, pp. 685-710.

[6] Z. P. Bažant and M. F. Kaplan, "Concrete at High Temperatures: Material Properties and Mathematical Models," Longman, Harlow, 1996.

[7] T. Hozjan, "Non-Linear Analysis of Composite Planar Structures Exposed to Fire," Ph.D. Dissertation, University of Ljubljana, Faculty of Civil and Geodetic Engineering, 2009.

[8] ISO 834, "Fire Resistance Tests-Elements of Building Constructions," International Standard ISO 834, 1975.

[9] Eurocode 2, "Design of Concrete Structures, Part 1.2, Structural Fire Design," European Committee for Standardization, 2004. 
[10] G. A. Khoury, C. E. Majorana, F. Pesavento and B. A. Schrefler, "Modelling of Heated Concrete," Magazine of Concrete Research, Vol. 54, No. 2, 2002, pp. 77-101.
[11] G. Williams-Leir, "Creep of Structural Steel in Fire: Analytical Expressions," Fire and Materials, Vol. 7, No. 2, 1983, pp. 73-78. 